\title{
PERENCANAAN PEMESANAN EKONOMIS PROBABILISTIK UNTUK MEMINIMASI BIAYA PERSEDIAAN
}

(Studi kasus: PT. Narmada Awet Muda, Nusa Tenggara Barat)

\author{
Eko Nursubiyantoro, Wawan K. Risal \\ Jurusan Teknik Industri, Fakultas Teknik Industri \\ Universitas Pembangunan Nasional "Veteran" Yogyakarta \\ J1. Babarsari No. 2 Tambakbayan, Depok, Sleman, \\ Yogyakarta 55281 \\ email : eko_nsby072@upnyk.ac.id
}

\begin{abstract}
ABSTRAK
Perusahaan dalam memenuhi permintaan pelanggan merupakan salah satu kunci sukses memenangkan kompetisi, PT Narmada Awet Muda (PT NAM) adalah salah satu perusahaan air minum dalam kemasan (AMDK) yang beroperasi di Lombok, NTB. Salah satu produk unggulan PT NAM adalah AMDK cup 220 ml. Ketersediaan karton box penting bagi produk AMDK cup $220 \mathrm{ml}$, karena tahap akhir produksi adalah pengemasan 48 gelas $220 \mathrm{ml}$ ke dalam karton box. Saat ini, perusahaan seringkali mengalami kekurangan bahan baku karton box dan kegiatan material handling gudang kurang baik. Tujuan dari penelitian adalah merencanakan jumlah pemesanan ekonomis probabilistik karton box AMDL cup 220 ml agar dapat memenuhi kebutuhan konsumen dan total biaya persediaan minimal.

Obyek penelitian adalah karton box kemasan AMDK cup ukuran 220 ml bagian PPIC, data harga karton box $(P)=R p .100 .000 /$ ikat, biaya pemesanan $(C)=R p 38,00 /$ pesan, biaya simpan $(H)$ 7,5\% bahan, leadtime 0,13 bulan. Model exponential smoothing berpola serupa dengan pola aktual, sehingga maka model digunakan sebagai dasar perhitungan persediaan periode mendatang.

Peningkatan service level hingga 99\% perusahaan menetapkan jumlah pemesanan optimal 4.541 ikat/bulan, frekuensi pemesanan 12 kali/bulan, titik pemesanan kembali 5.983 ikat dengan persediaan cadangan 5.392 ikat dan biaya total sebesar Rp. 5.515.199.900,12.
\end{abstract}

Kata kunci: Persediaan, Karton box, Probabilistik

\section{PENDAHULUAN}

Kemampuan perusahaan untuk memenuhi permintaan pelanggan merupakan salah satu kunci sukses untuk memenangkan kompetisi dengan perusahaan lain, terkait dengan hal itu maka kebijakan persediaan dalam suatu perusahaan akan memiliki resiko dan dampak yang tinggi terhadap kelangsungan kegiatan perusahaan. Tanpa adanya manajemen persediaan yang baik, maka pemasaran berpotensi kehilangan penjualan dan kepuasan pelanggan mengalami degradasi. Pada bagian departemen manufaktur, kehabisan persediaan bahan baku akan mengakibatkan dihentikannya proses manufaktur atau perubahan rencana jadwal produksi sehingga akan mengakibatkan pemborosan dan menimbulkan potensi kehabisan produk jadi.

PT Narmada Awet Muda (PT NAM) merupakan salah satu perusahaan air minum dalam kemasan (AMDK) yang beroperasi di Lombok, NTB. Berdasarkan data dari Dinas Kesehatan, terdapat 13 perusahaan AMDK yang telah terdaftar dan memiliki nomor registrasi MD untuk produk mereka. Pangsa pasar mayoritas adalah PT NAM dan 12 perusahaan lainnya adalah pasar lokal NTB, dan ditambah lagi dengan produk AMDK dari perusahaan nasional, menjadi suatu tantangan besar bagi perusahaan untuk memenangkan kompetisi pasar. PT NAM harus mampu menjaga ketersediaan produk-produknya agar dapat memuaskan konsumen. Salah satu produk unggulan PT NAM adalah AMDK cup $220 \mathrm{ml}$. Produk ini dijual dalam ukuran box berisi 48 gelas. Komponen pembentuk unit produk ini adalah cup octa, lid cup, sedotan, layer, $220 \mathrm{ml}$ air dan karton box. Sebagai produk unggulan, PT NAM harus menjaga ketersediaan seluruh bahan baku tersebut agar konsumen tidak berpindah ke produk sejenis dari merk lain saat produk tersebut kosong.

Salah satu bahan baku kemasan untuk produk AMDK adalah karton box, penyediaan bahan baku penolong tersebut oleh PT NAM dipercayakan pasokannya kepada PT Indo Tirta Abadi, Bekasi yang memerlukan waktu pemenuhan kurang lebih 4 hari. Ketersediaan karton box ini penting bagi produk AMDK 220 $\mathrm{ml}$, karena tahap akhir produksi adalah adalah 
pengemasan 48 gelas $220 \mathrm{ml}$ ke dalam karton box. Pada kondisi saat ini, yang terjadi di perusahaan bahan baku penolong ini seringkali mengalami kekurangan dan kegiatan material handling yang dilakukan oleh karyawan gudang kurang baik, sehingga banyak karton box yang mengalami kerusakan dan tidak dapat digunakan. Perusahaan akan memperbaiki manajemen persediaannya dengan cara melaksanakan proses pemesanan bahan baku penolong karton box yang seoptimal mungkin, sehingga diharapkan biaya total persediaan yang dibutuhkan juga minimal agar diperoleh margin profit yang lebih besar. Berdasarkan permasalahan tersebut maka dapat dirumuskan permasalahaanya adalah berapakah jumlah pemesanan ekonomis pada permintaan probabilistik karton box untuk memenuhi kebutuhan lantai produksi. Batasan masalah dalam penelitian ini adalah kapasitas mesin produksi tidak diperhitungkan, dengan asumsi permasalahan adalah leadtime pemesanan tetap, harga karton box tidak terpengaruh jumlah pemesanan, biaya pesan dan biaya simpan tetap, kekurangan persediaan ditangani dengan sistem backorder. Tujuan dari penelitian ini adalah merencanakan jumlah pemesanan ekonomis probabilistik karton box AMDL cup $220 \mathrm{ml}$ agar dapat memenuhi kebutuhan konsumen dengan total biaya persediaan minimal. Manfaat dari penelitian ini adalah sebagai bahan referensi perusahaan dalam proses pengambilan keputusan persediaan, secara akademis diharapkan memberi kontribusi ilmiah pada kajian tentang teori persediaan bagi aplikasi permintaan perusahaan yang bersifat probabilistik.

\section{LANDASAN TEORI}

Peramalan adalah fungsi bisnis yang memperkirakan penjualan dan penggunaan produk sehingga produk-produk itu dapat dibuat dalam kuantitas yang tepat (Gasperz, 2012). Peramalan adalah prediksi dari jumlah dari suatu unit yang akan diproduksi, dikirim, atau dijual (Closs \& Bowersox, 1996). Peramalan adalah prediksi yang mengarahkan perusahaan untuk mengetahui berapa jumlah produk yang akan dijual di masa depan, dasar pengambilan keputusan penting, dan juga sebagai dasar peren-canaan keputusan pembuatan jadwal produksi, inventori distribusi, pembelian, dan lain sebagainya sebagai fungsi dari permintaan pelanggan (Sheikh, 2002). Peramalan akurat bisa didapatkan dengan mengingat 4 prinsip yang berkaitan dengan akurasi peramalan yang ditulis oleh Sheikh (2002). Objek peramalan adalah data historis dari pemintaan suatu produk. Permintaan terbagi menjadi dua bagian, yaitu permintaan independent Permintaan terhadap material, parts, produk, yang bebas atau tidak terkait langsung dengan struktur bill of material untuk produk akhir atau item tertentu dan permintaan dependent Permintaan terhadap material, parts, atau produk yang terkait langsung terhadap atau diturunkan dari struktur bill of material untuk produk akhir atau item tertentu. Rentang waktu yang digunakan dalam berbagai tujuan peramalan adalah peramalan jangka panjang (2 sampai 10 tahun), jangka menengah (3 sampai 24 bulan), dan jangka waktu pendek (1 minggu sampai 3 bulan). Peramalan dilakukan dengan menggunakan berbagai macam model yang memiliki fungsi masing-masing sesuai dengan data dan tujuan peramalan. Model peramalan kualitatif merupakan model peramalan yang dilakukan dengan cara mempercayakan ramalan kepada ahli atau manajemen puncak, di mana ahli atau manajemen puncak tersebut menggunakan intuisi, opini, dan pengalaman masa lalu mereka untuk melakukan peramalan (Sheikh, 2002). Peramalan kualitatif ini sering dilakukan untuk peramalan jangka panjang, terutama saat faktor eksternal memiliki pengaruh besar dalam pengambilan keputusan tersebut. Shefler dan Meredith (1998) (dalam Sheikh, 2002) mengatakan Peramalan ini juga sering digunakan pada saat dimana data historis sangat terbatas bahkan tidak ada sama sekali. Beberapa jenis model peramalan yang termasuk dalam model kualitatif adalah Dugaan Manajemen, Riset Pasar, Metode Kelompok Terstruktur dan Analogi Historis. Model intrinsik dalam peramalan terdiri atas beberapa model yaitu :

\section{Moving Averages Model}

Model ini menggunakan sejumlah data aktual permintaan masa lalu untuk membangkitkan nilai ramalan untuk permintaan di masa yang akan datang.

$F_{t}=\sum_{i=1}^{n} \frac{s_{i-1}}{n}$

keterangan:

$F_{t}$ : peramalan moving averages periode $\mathrm{t}$

$S_{i-1}$ : permintaan untuk periode $i-1$

$\mathrm{n}$ : banyaknya periode data yang digunakan 
2. Weighted Moving Averages Model

Model ini lebih responsif terhadap perubahan karena data historis dari setiap periode diberikan bobot masing-masing sesuai dengan kronologi waktunya

$F_{t}=\frac{\sum_{t=1}^{n}\left(w_{t}\right)\left(D_{t-1}\right)}{\sum\left(w_{t}\right)}$

keterangan :

$F_{t}$ : peramalan wma untuk periode $\mathrm{t}$

$D_{t-1}$ : permintaan aktual periode sebelum

$w_{t}$ : nilai bobot untuk periode $\mathrm{t}$

\section{Exponential Smoothing Model}

Peramalan menggunakan model ini berdasarkan persamaan sebagai berikut :

$F_{t}=F_{t-1}+\alpha\left(A_{t-1}-F_{t-1}\right)$

keterangan :

$F_{t} \quad$ : nilai ramalan periode waktu ke-t

$F_{t-1}$ : nilai ramalan satu periode waktu lalu

$A_{t-1}$ : nilai aktual satu periode waktu lalu

$\alpha$ : konstanta pemulusan(smoothing constant)

4. Trend Line Analysis Model

Model analisis garis kecenderungan yang paling sederhana adalah menggunakan persamaan garis lurus sebagai berikut :

$F_{t}=a+b t$

keterangan :

$F_{t}$ : nilai peramalan pada periode $\mathrm{ke}-\mathrm{t}$

$a:$ intersep

$b$ : slope dari dari trend line

$t$ : indeks waktu

Slope dan intersep dari persamaan garis lurus dihitung menggunakan persamaan berikut :

$b=\frac{\sum t A-n(\bar{t})(\bar{A})}{\sum t^{2}-n(\bar{t})^{2}}$

$a=\bar{A}-b(\bar{t})^{2}$

keterangan :

$\bar{t}$ : nilai rata - rata dari $\mathrm{t}$

$A$ : data aktual permintaan

$\bar{A}$ : nilai rata - rata permintaan aktual

5. Exponential Smoothing With Trend Adjustment

Persamaan untuk model pemulusan eksponensial dengan mempertimbangkan kecenderungan adalah :

$F I T_{t}=F_{t}+T_{t}$

keterangan :

$F I T_{t}$ : peramalan mempertimbangkan trend

$F_{t} \quad$ : nilai ramalan exponential smoothing

$T_{t} \quad:$ trend correction

Persamaan untuk trend correction menggunakan konstanta beta $(\beta)$ dihitung sebagai berikut :

$T_{t}=(1-\beta) T_{t-1}+\beta\left(F_{t}-F_{t-1}\right)$ keterangan :

$\beta \quad$ : konstanta trend smoothing yang dipilih

$T_{t-1}$ : smoothed trend untuk periode t-1

$F_{t-1}$ : nilai ramalan exponential smoothing periode $\mathrm{t}-1$.

Persediaan adalah suatu istilah umum yang menunjukkan segala sumber daya yang ada dalam organisasi, yang disimpan dengan tujuan untuk mengantisipasi terjadinya pemenuhan permintaan (Tersine, 1994). Tujuan dilakukannya persediaan adalah sebagai berikut (Gasperz, 2012): Pelayanan pelanggan mencakup penyerahan barang tepat waktu, pengamanan terhadap ketidakpastian, dan memberikan keanekaragaman barang untuk memenuhi kebutuhan individu pelanggan. Efisiensi biaya dalam pembelian (diskon kuantitas dan biaya transportasi per unit material) dan produksi serta meminimumkan investasi dalam inventori. Pada sistem manufaktur, persediaan barang terdiri dari 3 bentuk sebagai berikut : persediaan bahan baku, persediaan barang setengah jadi, dan persediaan barang jadi, yang berguna untuk mengurangi resiko keterlambatan datangnya barang, mempertahankan stabilitas operasional perusahaan, mencapai penggunaan mesin yang optimal, dan emberikan pelayanan terbaik bagi konsumen.

Sistem persediaan yang digunakan dalam penelitian ini adalah independent demand system dengan mempertimbangkan model probabilistik, karena demand diperlakukan sebagai variabel acak. Persediaan untuk permintaan independent terbagi menjadi working stock sebagai persediaan yang digunakan selama periode waktu tertentu, dan safety stock sebagai persediaan pengaman. Rata-rata working stock adalah setengah jumlah pemesanan (lot size), yang bisa ditentukan dengan formulasi jumlah pemesanan ekonomis atau yang lainnya. Safety stock tidak selalu tergantung dengan lot size.

Persamaan biaya persediaan dengan model jumlah pemesanan ekonomis probabilistik single item adalah sebagai berikut (Tersine, 1994):

1. Jumlah pemesanan optimal

Jumlah pemesanan optimal digunakan model EOQ single item. Persamaan yang digunakan untuk adalah :

$Q^{*}=\sqrt{\frac{2 . C . R}{H}}$ 
keterangan :

$Q^{*}$ : jumlah pemesanan optimal

$C$ : biaya pemesanan

$R$ : perkiraan kebutuhan barang satu periode

$H$ : biaya penyimpanan

2. Ekspektasi biaya kekurangan persediaan Karena biaya kekuangan persediaan tidak diketahui, maka ditentukan nilai $S L_{u}$ (service per unit demanded). Persamaan yang digunakan untuk menghitung ekspektasi biaya kekurangan persediaan :

$S L_{u}=\frac{1-E(M>B)}{Q} \rightarrow E(M>B)=Q \cdot\left(1-S L_{u}\right)$

keterangan :

$E(M>B)$ : ekspektasi biaya kekurangan persediaan

$Q$ : jumlah pemesanan optimal

$S L_{u}:$ service per unit demanded

Setelah diketahui $E(M>B)$, maka dapat dicari nilai $z$ dan $P(M>B)$ dengan menggunakan Tabel $z$.

3. Titik pemesanan kembali (reorder point)

Reorder point adalah suatu kondisi di mana persediaan barang pada jumlah tertentu harus dilakukan pemesanan kembali barang karena jumlahnya tidak mencukupi selama waktu tunggu pengadaan barang yang akan mengganggu jalannya penjualan. Dari nilai z pada poin 2 diatas akan diperoleh nilai reorder point untuk kasus backorder:

$B=\bar{M}+z . \sigma$

keterangan :

$B$ : reorder point

$\bar{M}$ : rata - rata permintaan selama lead time

$Z$ : safety factor

$\sigma$ : standar deviasi permntaan selama lead time

4. Jumlah persediaan cadangan (safety stock)

Formula untuk menentukan jumlah persediaan cadangan untuk kasus backorder adalah :

$S S=B-\bar{M}$

keterangan :

$S S$ : jumlah persediaan cadangan

5. Biaya pembelian barang

Besanya biaya pembelian barang dapat dihitung menggunakan persamaan:

$\mathrm{Pc}=\mathrm{R} . \mathrm{P}$

keterangan :

$P c$ : biaya pembelian total selama satu tahun

$R$ : jumlah permintaan selama satu tahun

$P$ : biaya pembelian per unit
6. Biaya penyimpanan barang

Besarnya biaya penyimpanan barang dihitung sebagai berikut:

$H c=H \cdot \frac{Q}{2}=P \cdot f \cdot \frac{Q}{2}$

keterangan :

$H c$ : total biaya penyimpanan selama satu tahun

$f$ : fraksi biaya simpan

$Q$ : jumlah pemesanan optimal

7. Biaya pemesanan barang

Besarnya biaya pemesanan barangdapat dihitung sebagai berikut:

$C c=\frac{R . C}{Q}$

keterangan :

$\mathrm{Cc}$ : total biaya pemesanan barang

8. Biaya backorder per unit

Biaya backorder per unit dapat dihitung sebagai berikut:

$P(M>B)=\frac{H \cdot Q}{A \cdot R} \rightarrow A=\frac{H \cdot Q}{R \cdot P(M>B)}$

keterangan :

$A$ : biaya backorder per unit

$P(M>B)$ : probailitas kekurangan persediaan

$P(M>B)$ diperoleh dengan menggunakan Tabel $z$ setelah diperoleh nilai $E(M>B)$.

9. Biaya safety stock

Ekspektasi biaya safety stock kasus backorder dengan biaya kekurangan per unit adalah :

$T C_{S}=H(B-\bar{M})+\frac{A \cdot R \cdot E(M>B)}{Q}$

keterangan :

$T C_{S}$ : total biaya safety stock

10. Biaya keseluruhan

Besarnya biaya keseluruhan dapat dihitung dengan menggunakan persamaan :

$T C=P c+H c+C c+T C_{s}$

keterangan :

$T C$ : total biaya keseluruhan

\section{METODOLOGI PENELITIAN}

Obyek dalam penelitian ini adalah karton box untuk kemasan AMDK cup ukuran $220 \mathrm{ml}$ pada bagian Production Planning and Inventory Control (PPIC) PT Narmada Awet Muda, Desa Montong Selat, Kecamatan Narmada, Lombok, NTB, Indonesia. Data yang dikumpulkan dalam penelitian ini adalah data yang diperoleh dengan melakukan pengamatan langsung di gudang karton penyimpanan karton box, melakukan wawancara langsung kepada kepala bagian PPIC PT Narmada Awet Muda, tentang kondisi aktual dan kendala yang dihadapi dalam manajemen persediaan yang 
telah diterapkan serta mempelajari data-data yang berkaitan dengan penelitian pada dokumen perusahaan.

Pengolahan data dalam penelitian ini dibagi menjadi dua kelompok, yaitu pengolahan data peramalan permintaan, dan pengolahan data untuk manajemen persediaan. Berikut langkahlangkah dari masing-masing pengolahan data :

1. Langkah pengolahan data peramalan

Langkah-langkah pengolahan data untuk peramalan adalah sebagai berikut:

a) Identifikasi pola historis dari data aktual permintaan.

b) Memilih model peramalan yang sesuai dengan pola historis permin-taan

c) Melakukan perhitungan dengan menggunakan model yang telah dipilih.

d) Melakukan analisis data berdasarkan perhitungan peramalan model peramalan yang dipilih.

e) Memilih model peramalan yang tepat berdasarkan hasil analisa data yang dilakukan.

2. Langkah pengolahan data untuk manajemen persediaan.

Langkah-langkah pengolahan data untuk manajemen persediaan adalah sebagai berikut :

a) Menentukan jumlah pemesanan optimal untuk memenuh permintaan

b) Menentukan ekspektasi biaya kekurangan persediaan $E(M>B)$. Sehingga dapat ditentukan $\sigma_{M}=\sigma_{D} \times \sqrt{L}$ dan $\bar{M}=\sum M \times$ $L$ sehingga dapat dicari nilai $P(M>B)$ dengan menghitung nilai $E(Z)$ dengan formula $E(Z)=\frac{Q^{*} \times\left(1-S L_{u}\right)}{\sigma_{M}} \quad$ kemudian dicari pada Tabel $z$.

c) Menentukan titik pemesanan kembali (reorder point) dengan Persamaan (11)

d) Menetapkan jumlah persediaan cadangan (safety stock) dengan Persamaan (12)

e) Menghitung total biaya pembelian dengan Persamaan (13)

f) Menghitung total biaya penyimpanan dengan Persamaan (14)

g) Menghitung total biaya pemesanan dengan Persamaan (15)

h) Menghitung biaya backorder per unit dengan Persamaan (16)

i) Menghitung total biaya safety stock dengan Persamaan (17)

j) Menghitung total biaya keseluruhan dengan Persamaan (18)
Setelah pengolahan data dilakukan, maka hasilnya dianalisa untuk kemudian diambil kesimpulan dan saran yang dapat diberikan kepada peneliti lanjutan serta perusahaan.

\section{HASIL DAN PEMBAHASAN}

Data kebutuhan penggunaan karton box untuk AMDK cup $220 \mathrm{ml}$ :

Tabel 4.1 Data kebutuhan karton AMDK cup $220 \mathrm{ml}$

\begin{tabular}{|c|l|c|}
\hline No. & \multicolumn{1}{|c|}{ Bulan } & $\begin{array}{c}\text { Jumlah Pemakaian } \\
(\text { Pcs })\end{array}$ \\
\hline 1 & Januari & 27.841 \\
\hline 2 & Februari & 53.846 \\
\hline 3 & Maret & 80.741 \\
\hline 4 & April & 122.348 \\
\hline 5 & Mei & 124.743 \\
\hline 6 & Juni & 122.871 \\
\hline 7 & Juli & 128.938 \\
\hline 8 & Agustus & 87.854 \\
\hline 9 & September & 107.568 \\
\hline 10 & Oktober & 141.703 \\
\hline 11 & November & 33.554 \\
\hline 12 & Desember & 34.115 \\
\hline & Jumlah & 1.106 .122 \\
\hline
\end{tabular}

Data berikutnya adalah harga bahan baku karton box $(\mathrm{P})=$ Rp. 100.000/ikat $(1$ ikat $=20$ lembar), biaya pemesanan $(\mathrm{C})=\mathrm{Rp} 38,00 /$ sekali pesan, biaya simpan $(\mathrm{H}) 7,5 \%$ harga bahan, leadtime 0,13 bulan. Data hasil peramalan permintaan dipilih dari tiga model peramalan, model exponential smoothing dengan konstanta pemulusan $(\alpha)=0,85$ memiliki keandalan yang lebih baik dibandingkan dengan kedua model lainnya (Gambar 4.1), hal tersebut dapat diketahui dengan melihat sebaran nilai tracking signal pada peta kontrol tracking signal ES ; $\alpha=0,85$ lebih merata, hal ini berarti komposisi antara postive error dan negative error seimbang.

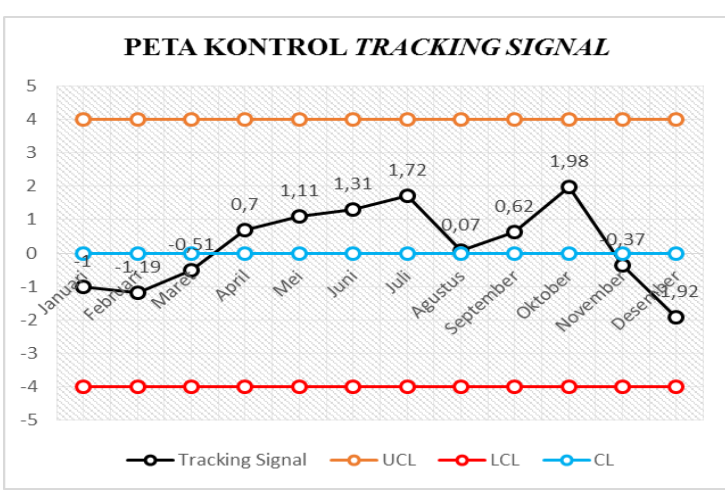

Gambar 4.1 Peta Kontrol Tracking Signal ES; $\alpha=0,85$

Pola distribusi dari peramalan tersebut kemudian dibandingkan dengan pola historis 
dari data aktual dan akan berbentuk seperti Gambar 4.2.

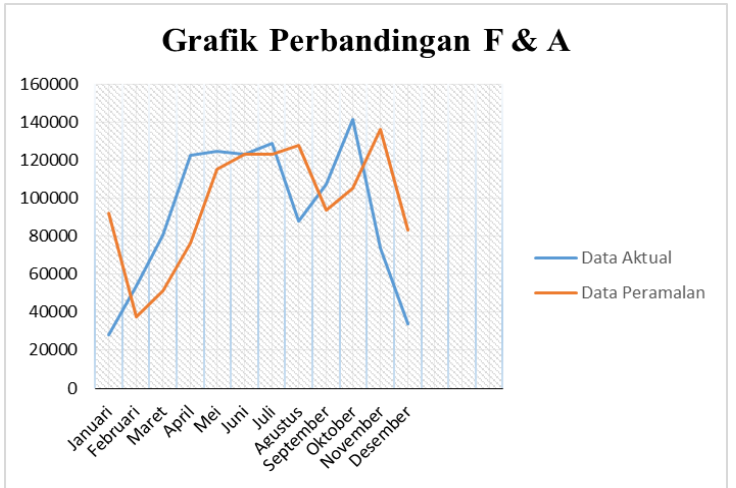

Gambar 4.2 Perbandingan Hasil Ramalan ES ; $\alpha=0,85$ dengan Data Aktual

Data hasil peramalan kebutuhan karton box untuk AMDK cup $220 \mathrm{ml}$ :

Tabel 4.2 Data hasil peramalan kebutuhan karton AMDK cup $220 \mathrm{ml}$

\begin{tabular}{|c|l|r|}
\hline No. & \multicolumn{1}{|c|}{ Bulan } & $\begin{array}{c}\text { Jumlah Pemakaian } \\
(\text { Pcs })\end{array}$ \\
\hline 1 & Januari & 92.177 \\
\hline 2 & Februari & 37.492 \\
\hline 3 & Maret & 51.393 \\
\hline 4 & April & 76.393 \\
\hline 5 & Mei & 115.447 \\
\hline 6 & Juni & 123.349 \\
\hline 7 & Juli & 122.943 \\
\hline 8 & Agustus & 128.077 \\
\hline 9 & September & 93.888 \\
\hline 10 & Oktober & 105.516 \\
\hline 11 & November & 136.275 \\
\hline 12 & Desember & 82.963 \\
\hline & Jumlah & 1.165 .013 \\
\hline
\end{tabular}

Perhitungan persediaan dilakukan setelah pengolahan data peramalan berdistribusi normal, maka perhitungan persediaan dapat dilanjutkan. Hasil perhitungan persediaan adalah sebagai berikut:

1. Perhitungan jumlah pemesanan optimal:

Perkiraan kebutuhan karton box per tahun adalah :

$R=\frac{1.089 .520}{20}=54.476 \mathrm{ikat}$

Sehingga jumlah pemesanan ekonomis dari karton box AMDK cup $220 \mathrm{~mL}$ adalah :

$Q^{*}=\sqrt{\frac{2 . C . R}{P . f}}=\sqrt{\frac{2.38 .54476}{100000.0,075}}=23,49 \approx 24$ ikat

Dengan frekuensi pemesanan sebesar $=\frac{54476}{24}=$ $2269,83 \approx 2270$ kali dalam setahun, atau dalam sebulan $=\frac{2270}{12}=189,12$ kali, jika dilakukan per hari $=\frac{189,12}{24}=7,88$ kali, karena bagian pembelian bekerja 6 hari dalam seminggu. Karena pemesanan lebih dari 7 kali per hari dirasa tidak efisien untuk dilakukan, maka jumlah pemesanan optimal ditingkatkan menjadi :

$Q^{*}=7,88 \times 24=174,24 \approx 189,2 \mathrm{ikat} / \mathrm{hari}$ atau

$Q^{*}=189,2 \times 24$ hari $=4.540,8 \approx 4.541$

ikat/bulan.

Dengan frekuensi pemesanan $=54.476 / 4.541$ $=11,99 \approx 12 \mathrm{kali} / \mathrm{bulan}$.

2. PT Narmada Awet Muda ingin meningkatkan service level perusahaan $\left(S L_{u}\right)$ sebesar $99 \%$, sehingga dapat diketahui $E$ $(M>B)$ :

$E(M>B)=Q^{*}\left(1-S L_{u}\right)$

$E(M>B)=4541(1-0,99)=45,41$

Maka dapat diketahui nilai $Z=1,78$ dan $P(M>B)=0,0373$.

3. Titik pemesanan kembali $(B)$ adalah :

$B=Z \cdot \sigma_{M}+\bar{M}$, dengan

$\bar{M}=\frac{\sum M}{12} \times L=\frac{54476}{12} \times 0,13=590,16$

$\approx 591$, Maka

$B=1,78 \times 3.028,887+591=5.982,41 \approx$ 5.983 ikat.

4. Jumlah persediaan cadangan sebesar :

$S S=B-\bar{M}$

$S S=5983-591=5.392 \mathrm{ikat}$

5. Total biaya pembelian yang dikeluarkan perusahaan untuk menjalankan rencana ini adalah :

$$
\begin{aligned}
P c & =R \times P=54.476 \times 100.000 \\
& =\text { Rp. } 5.447 .600 .000 / \text { tahun }
\end{aligned}
$$

6. Total biaya simpan adalah :

$$
\begin{aligned}
H c & =P . f \cdot \frac{Q^{*}}{2}=(100.000)(7,5 \%) \frac{4541}{2} \\
& =\operatorname{Rp} 17.028 .750 / \text { tahun }
\end{aligned}
$$

7. Total biaya yang dikeluarkan untuk pemesanan adalah :

$C c=\frac{R . C}{Q^{*}}=\frac{54476.38}{4541}=$ Rp. 455,86

8. Biaya backorder per unitnya adalah :

$$
\begin{aligned}
A & =\frac{H \cdot Q^{*}}{R \cdot P(M>B)} \\
A & =\frac{100000 \times 7,5 \% \times 4541}{54476 \times 0,0373}=\text { Rp. } 16.760,95
\end{aligned}
$$

9. Biaya safety stock yang dikeluarkan adalah sebesar :

$$
T C_{S}=H(B-\bar{M})+\frac{A \cdot R \cdot E(M>B)}{Q^{*}}
$$


$T C_{s}=100.000 \times 7,5 \%(5983-591)$

$$
+\frac{16.760,95 \times 54.476 \times 45,41}{4541}
$$

$T C_{S}=$ Rp. 49.570.695,12/tahun

10. Total biaya yang dikeluarkan PT Narmada Awet Muda untuk perencanaan persediaan:

$T C=P c+H c+C c+T C_{s}$

$T C=5.447 .600 .000+17.028 .750+455,86$

$$
+49.570 .695,12
$$

$T C=$ Rp. 5.515.199.900,98

Model peramalan exponential smoothing memiliki pola distribusi permintaan yang serupa dengan pola historis permintaan aktual, sehingga model ini dapat digunakan sebagai dasar perhitungan perencanaan persediaan pada periode mendatang. Hasil dari peramalan menghasilkan data perkiraan kebutuhan tahunan karton box AMDK cup 220 $\mathrm{mL}$ adalah 1.089.520 lembar atau 54.476 ikat karton box. Sesuai tujuan perusahaan untuk memenuhi tingkat pelayanan sebesar $99 \%$ maka ditetapkan jumlah pemesanan optimal dipesan sebesar $4.541 \mathrm{ikat} / \mathrm{bulannya,} \mathrm{untuk}$ memenuhi permintaan tersebut frekuensi pemesanan dilakukan 12 kali dalam sebulan atau 1 kali pemesanan dalam 2 hari dengan pemesanan dilakukan pada saat jumlah persediaan mencapai titik 5.983 ikat. Penanganan fluktuasi permintaan perusahaan perlu menyediakan cadangan pengaman sejumlah 5.392 ikat. Total biaya perssediaan yang dibutuhkan sebesar Rp. 5.515.199.900,98 dengan rincian biaya pembelian adalah sebesar Rp. 5.447.600.000/tahun, biaya penyimpanan sebesar Rp. 17.028.750/tahun, biaya pemesanan untuk sejumlah persediaan tersebut adalah Rp. 455,86, dan total biaya untuk safety stock adalah sebesar Rp. 49.570.695,12/tahun.

\section{KESIMPULAN}

Peningkatan service level perusahaan hingga $99 \%$ periode mendatang harus dilakukan perusahaan dengan menetapkan jumlah pemesanan optimal sebesar 4.541 ikat/bulan dengan frekuensi pemesanan sebanyak 12 kali/bulan, titik pemesanan kembali 5.983 ikat dengan persediaan cadangan 5.392 ikat. Biaya total persediaan sebesar Rp. 5.515.199.900,12 untuk jangka waktu 1 tahun, diharpkan mampu meningkatkan tingkat pelayanan yang meningkatkan laba perusahaan. Penelitian ini mengasumsikan leadtime pemesanan tetap, harga bahan tidak terpengaruh jumlah pemesanan, maka untuk penelitian lanjut sebaiknya memasukkan data kondisi riil seperti leadtime dan harga bahan yang tergantung pada jumlah pemesanan.

\section{DAFTAR PUSTAKA}

Bowersox, D \& Closs, D., 1996, Logistical Management : The Integrated Supply Chain Process, International ed., McGraw-Hill Book, Co, Singapore.

Gasperz, V., 2012, All-In-One ${ }^{\circledR}$ : Production And Inventory Management For Supply Chain Professionals, edisi revisi., Vinchristo Publi-cation, Bogor.

Sheikh, K., 2001, Manufacturing Recource Planning (MRP II) With Introductio To ERP, SCM and CRM, International ed., McGraw-Hill, Co., Singapore.

Tersine, R., 1994, Priciples of Inventory And Materials Management, 4th ed., PrenticeHall, Inc., New Jersey. 